\title{
TECENDO RELAÇÕES ENTRE O CONCEITO DE "MASSA APERCEPTIVA" DE JAKUBINSKIJ E ALGUMAS IDEIAS DE VIGOTSKI
}

\author{
WEAVING RELATIONS BETWEEN THE CONCEPT OF APERCEPTIVE MASS OF \\ JAKUBINSKIJ AND SOME IDEAS OF VIGOTSKI
}

\begin{abstract}
Silvane Maria Pereira Brandão
UNESP - Marília (Doutoranda em Educação na UNESP - Câmpus de Marília, Mestre em Literatura Inglesa pela Universidade Federal de Santa Catariana - UFSC, Especialista em Docência do Ensino Superior pela Universidade Norte do Paraná - UNOPAR, Graduada em Línguas e Literaturas Modernas - Variante Português/Inglês pela Universidade de Lisboa, IFRO/Reitoria em Porto Velho-RO, Brasil. silvane7mpb@gmail.com

(iD)

Vanessa Milani Labadessa

UNESP - Marília (Doutoranda em Educação na UNESP _ Câmpus de Marília, Mestre em Psicologia pela Universidade Federal de Rondônia - UNIR, Especialista em Psicologia Histórico-Cultural pela Universidade Estadual de Maringá - UEM, Graduada em Psicologia pela Universidade Estadual de Maringá - UEM, Docente do Instituto Federal de Educação Ciência e Tecnologia de Rondônia - área psicologia/Câmpus Ariquemes, em Ariquemes -RO, Brasil vanessa.milani@ifro.edu.br,

(iD) Márcia Mendes de Lima

UNESP - Marília (Doutoranda em Educação na UNESP - Câmpus de Marília, Mestre em Ciências Ambientais pela Universidade Federal de Rondônia - UNIR, Especialista em Metodologia e Didática do Ensino Superior - Faculdade Integrada de Ouro Preto do Oeste UNEOURO, Graduada em Ciências Biológicas pela Faculdade de Educação de Porto Velho, Docente do Instituto Federal de Educação Ciência e Tecnologia de Rondônia - IFRO/Câmpus Ariquemes -área biologia, Coordenadora de área do Programa Residência Pedagógica - Capes, em Ariquemes - RO, Brasil. marcia.lima@ifro.edu.br
\end{abstract}

\begin{abstract}
Resumo: Jakubinskij em sua obra "Sobre a Fala Dialogal" apresenta o conceito massa aperceptiva. O objetivo deste artigo é tecer relações entre algumas ideias dos pensadores da Teoria Histórico-Cultural e esse conceito, em uma tentativa de ampliá-lo para além da linguagem, tentando perceber em que aspectos eles se relacionam. Para isso foi feita uma pesquisa de cunho bibliográfico que se baseou em Jakubinskij (2015); Vigostski (2001) e Leontiev (1978), que buscou relacionar os conceitos apresentados e defendidos pelos pensadores citados, fazendo uma investigação comparativa. As categorias envolvidas são: linguagem, meio e sentido. Ao final deste processo comparativo foi possível associar os conceitos em três aspectos: a importância do meio na compreensão do mundo e no desenvolvimento humano, a semelhança de massa aperceptiva entre falantes e a zona de desenvolvimento proximal, e a relação do sentido vigotskiano e a massa aperceptiva de Jakubinskij, sem esgotar as possibilidades, mas apenas iniciando uma discussão.
\end{abstract}

Palavras-chave: Massa aperceptiva. Teoria Histórico-Cultural. Vigotski. Comparação.

\begin{abstract}
Jakubinskij in his book "About Dialogical Speech" presents the concept of aperceptive mass. The objective of this article is to bring into evidence the relation between some thinkers of Historical Cultural Theory and this concept. In an attempt of wide it beyond language, trying to understand in which aspects they relate. To do it a bibliography research was done, based on Jakubinskij (2015); Vigostski (2001) and Leontiev (1978). This research try to relate the concepts presented and defended by the thinkers mencioned, doing an comparative research. The categories involved are: language, medium and sense. At the end of this comparative process it was possible to associate them in three aspects: The importance of environment in humam comprehension of the world and in the human development, the similar aperceptive mass and the proximal developmental zone, and the relation between the vigotskian sense and the aperceptive mass of Jakubinskij, without finish possibilities, but only starting a discussion.
\end{abstract}

Key words: Aperceptive mass. Historical Cultural Theory. Vigotski. Comparison.

\section{Introdução}

$\mathbf{U}$ m conceito novo traz consigo adaptações e leva a uma reorganização de informações que ocorrem nos conceitos prévios de uma pessoa. Há uma análise das novas informações e uma procura em aplicá-las. Ao conhecer o conceito de 
massa aperceptiva de Jakubisnskij (2015) vem à mente a ideia das vivências e da influência social em tudo que o ser humano é, na pessoa que ele se torna.

Jakubinskij em sua obra "Sobre a Fala Dialogal" apresenta esse conceito de massa aperceptiva, definido como: "o conteúdo do psiquismo de determinado indivíduo, por meio do qual ele assimila uma estimulação externa" (JAKUBINSKIJ, 2015, p. 88). Esta massa aperceptiva seria, portanto, resultado de todas as vivências, de todas as memórias e do ambiente onde se vive. Ela consiste naquilo que a pessoa traz consigo quando vivencia ou aprende alguma coisa.

Desta forma, é possível associar esse conceito com alguns aspectos da Teoria HistóricoCultural, de Vigotski e seus seguidores, ampliando a área de influência desse conceito. É por meio das vivências que o ser humano faz a leitura do mundo que o rodeia e aprende com tudo que lhe é apresentado a cada dia. As vivências determinam como um indivíduo vai "ler" cada situação que surge em sua vida.

Segundo Vigotski (2010), o desenvolvimento sistêmico da humanidade se deu ao longo da história. Esse desenvolvimento é transmitido através das interações sociais, ou seja, se não houver essa interação o homem não terá em si os saberes construídos. O autor defende que o homem é um ser social e que o meio social é fonte para o desenvolvimento humano e fundamental para seu aprendizado.

Este artigo pretende apontar as semelhanças entre o conceito de massa aperceptiva e os princípios da Teoria Histórico-Cultural, e, para isso, será feita uma pesquisa de cunho bibliográfico que busca definir os conceitos dos autores/pensadores, tecendo as relações que puderem ser encontradas entre eles.

\section{Fundamentação teórica}

Segundo Jakubinskij (2015), todos os indivíduos têm uma massa aperceptiva, que se reporta às experiências anteriores que o sujeito vivenciou e permite identificar novos conceitos linguísticos, a partir dos que já se conhecia, assim “[...] Sem levar em conta todos esses fatores e sem estudar as manifestações multiformes da fala que lhe corresponde funcionalmente, não é possível estudar uma língua como fenômeno dado diretamente à percepção viva, nem desvelar a gênese e a história" (JAKUBINSKIJ, 2015, p. 50).

O autor defende em sua obra que nossa percepção e nossa compreensão da fala sofrem influências de nossas experiências vividas, dessa forma, a massa aperceptiva é aquilo que uma pessoa 
traz consigo no momento em que vai presenciar uma nova situação, é ela quem vai determinar a maneira como a pessoa vai enfrentar ou vivenciar a nova situação que surge. Ele afirma:

No início de uma conversação a massa aperceptiva de um dado interlocutor é parcialmente constituída pelo que lhe é próprio e constante, mas ela se complexifica pelo aporte aperceptivo próprio desse momento, pela percepção do interlocutor e da situação, e finalmente, por uma representação mais ou menos concreta do assunto da conversação (JAKUBINSKIJ, 2015, p. 97)

O autor condiciona a diversidade da linguagem à variedade dos comportamentos sociais, que tem fundamentos psicológicos e sociológicos, dependendo da interação do organismo com o coletivo, ainda confere a diversidade linguística das línguas ao "peso dos fatores psicológicos: fala normal, anormal ou sob influência do elemento emocional ou intelectual” (JAKUBINSKIJ, 2015, p. 50).

Na mesma ótica, propõe que cada indivíduo, ao se comunicar, cria a massa aperceptiva, que se compõe de um "[...] conjunto das experiências e saberes anteriores necessários à compreensão e à interpretação de uma ação ou de um enunciado [...]" (JAKUBINSKIJ, 2015, p. 97). Quanto mais elementos próximos nas massas aperceptivas entre os indivíduos, maior a aproximação e compreensão do discurso; e o princípio se inverte, segundo o autor, quando há distanciamento entre as massas aperceptivas, haverá dificuldade de compreensão (JAKUBINSKIJ, 2015).

Apesar de esse autor tratar em sua obra da linguagem especificamente, ao tratar do conceito em evidência aqui, é possível ampliá-lo para além da linguagem, pois ele se assemelha muito ao conceito principal que permeia a Teoria histórico-cultural que é a influência do meio no desenvolvimento do ser humano. As vivências são fundamentais para a humanização, tudo que uma pessoa vive vai marcando profundamente sua existência, pois, como já foi afirmado, o ser humano é um ser social (Vigotski, 2010).

Vigotski (2006) defende que a linguagem é uma ferramenta mediadora que viabiliza a comunicação entre os indivíduos, permite compartilhamento de significados por determinado grupo cultural, de eventos e de situações à sua volta, orienta a percepção e a interpretação dos objetos. Com sua função comunicativa, além de contribuir para que o homem vivencie um processo de interlocução com seus semelhantes, possibilita ao homem abstrair e generalizar a realidade através de atividades mentais e complexas. Assim vai construindo conceitos.

Além disso, estudos Vigotskianos que abordam a linguagem apontam uma importante contribuição desse autor. A linguagem é percebida não apenas como uma forma de comunicação, mas também como uma função reguladora do pensamento, porque "o conceito de fala se refere à linguagem em ação, à produção linguística do falante no discurso. [...] a fala tem uma conotação de 
ação e envolve o contexto" (GOLDFELD, 1997, 16). Nesse ponto, Jakubinskij e Vigotski conversam.

Ainda com relação à fala:

Vigotski introduz, além do significado, a noção de sentido. O sentido é um aspecto particular do signo por ser formado a partir das relações interpessoais vivenciadas pelo indivíduo e da sua história. O sentido depende da história do indivíduo e do contexto no qual o diálogo ocorre, ele não preexiste. (GOLDFELD, 1997, 21)

Para Vigotski (2010, p. 697-698), “o homem é um ser social que fora da interação com a sociedade ele nunca desenvolverá em si aquelas qualidades, aquelas propriedades que desenvolveria como resultado do desenvolvimento sistemático de toda a humanidade", desta forma, o meio social é vital para o aprendizado e torna-se fonte para o desenvolvimento humano. A criança faz parte de uma organização familiar inserida em uma sociedade, com uma cultura particular, em um momento histórico específico e todo esse contexto a marca profundamente. Esse momento histórico é, para Saviani (2005, p.13), essencial, e se reflete na escola, pois, “o trabalho educativo é o ato de produzir direta e intencionalmente, em cada indivíduo singular, a humanidade que é produzida histórica e coletivamente pelo conjunto dos homens".

Nessa perspectiva, percebemos que "o desenvolvimento humano é uma possibilidade, pois depende das experiências - das vivências e das aprendizagens - que as gerações mais velhas propõem para as novas gerações" (TEIXEIRA; BARCA, 2017, p. 33). Com o entendimento de que as crianças aprendem desde que nascem nas relações estabelecidas com pessoas e objetos da cultura, sua humanidade é forjada com base nas aprendizagens que realiza no decorrer de sua vida. Ao longo da infância, as crianças passam por transformações que mudam a maneira como se relacionam com o mundo da cultura e das pessoas e, por isso, mudam a forma de aprender e também de perceber ou "ler" o mundo a sua volta (VYGOTSKI, 2010).

Essa afirmação reitera o entendimento de que desenvolvimento humano deve ser incitado de maneira intencional de modo que desde a infância os seres humanos "reproduzam as máximas qualidades humanas", conforme refere Mello (2015). Dessa forma, "a ação escolar permite que se acrescentem novas determinações que enriquecem as anteriores, e o acesso à cultura erudita possibilita a apropriação de novas formas por meio das quais se podem expressar os próprios conteúdos do saber popular" (SAVIANI, 2005, p. 21). Cada experiência, cada lembrança, vai criando marcas que ficam retidas no ser humano, o que possibilita que cada um tenha uma impressão diferente da realidade que o cerca e que cada momento cultural será "lido" de uma maneira diferente por cada um em particular.

Segundo Lima (2017, p. 114) cada vivência “fortalecida pelo afeto" vai marcando a pessoa e, nessas relações, a criança vai gradualmente se tornando um participante do gênero humano, 
aperfeiçoando suas capacidades psicológicas em níveis cada vez mais complexos e sofisticados, sendo assim, cada vez mais capaz de perceber com eficiência a realidade que a cerca.

A escola proporciona uma gama rica de vivências e lá o professor é a ponte de acesso da criança à cultura de maneira em que a criança se torne parte dela e se aproprie de seu conteúdo, trazendo-o sempre consigo. É nessa "atividade socialmente mediada que a criança atribui sentido aos bens culturais que passa a conhecer" (LIMA, 2017, p.125), por isso, a tarefa essencial de uma escola comprometida com a formação omnilateral dos indivíduos é mediar, pela atividade intelectual e prática do professor, a relação entre o sujeito e o objeto do acervo de significações construído histórico-socialmente (LIMA, 2016, p.118).

Nesse processo educativo potencialmente humanizador, o professor considera o conhecimento já apropriado pela criança (sua massa aperceptiva) e intervém intencionalmente nas tarefas que ela não consegue fazer sozinha, para ajudá-la a perceber o mundo a sua volta e aprender com suas vivências. Nas palavras de Lima (2016, p.118):

[...] considerando que a criança já sabe, o professor a ajuda nas tarefas que ela não pode
realizar sozinha, buscando incidir o novo conhecimento, na zona de desenvolvimento
próximo caracterizada pelo desenvolvimento que está próximo de acontecer. Sob esse
prisma, redimensiona-se a própria ideia do que seja a criança: um sujeito capaz de se
relacionar, interagir, se comunicar, internalizar conhecimentos atribuindo sentido a eles,
a partir das relações sociais de que participa e do lugar que ocupa nessas relações. A
educação na infância pode, assim, deflagrar o desenvolvimento cultural da criança, ao
romper os limites da natureza biológica, promovendo o processo de formação da
natureza social humana

De acordo com Vigotski (2012), há dois níveis de desenvolvimento, o primeiro nível pode ser chamado de nível de desenvolvimento efetivo, esse "[é] o nível de desenvolvimento das funções psicointelectuais da criança que se conseguiu como resultado de um específico processo de desenvolvimento já realizado" (VIGOTSKI, 2012, p. 111), ou seja, os produtos finais do desenvolvimento; o segundo nível é a zona de desenvolvimento próximo ou potencial que é o que a criança é capaz de fazer com o auxílio dos adultos. Ainda segundo sintetiza o autor:

O que a criança pode fazer hoje com o auxílio dos adultos poderá fazê-lo amanhã por si só. A área de desenvolvimento potencial permite-nos, pois, determinar os futuros passos da criança e a dinâmica de seu desenvolvimento e examinar não só o que o desenvolvimento já produziu, mas também o que produzirá no processo de maturação (VIGOTSKI, 2012, p.113).

Esse envolvimento completo do sujeito, nos aspectos físicos, intelectuais e afetivos, pode caracterizar aprendizagens motivadoras de seu pleno desenvolvimento cultural. Aquino e Cunha 
(2016, p. 187) explicam que a "aprendizagem possui tanto um caráter intelectual quanto emocional, já que ela envolve a personalidade como um todo”.

Assim, é possível perceber que tanto Jakubinskij quanto Vigotski falam de coisas semelhantes em seus textos. Essa associação será melhor explicada no próximo tópico.

\section{Pontos comuns entre os conceitos}

Analisando e confrontando os conceitos apresentados neste artigo podemos verificar que há uma relação interessante entre eles. Os dois conceitos se assemelham quando se consideraram as vivências que um indivíduo possui como determinantes, todavia, ao longo da vida, esse ser sempre irá se deparar com novas informações e experiências colocadas diante deles pelo meio em que está inserido. Nesse sentido, segundo Mello (2015), a bagagem que carregamos determina aquilo que somos capazes de compreender ou aprender; é através do conhecimento anteriormente elaborado que o indivíduo assimila outros conhecimentos, e isso geralmente ocorre com a intermediação de alguém ou algo (como por exemplo, um livro).

Todas as experiências de vida ou linguísticas de um indivíduo constituem a sua massa aperceptiva. Segundo Jakubisnkij, para que duas pessoas se entendam é preciso que suas massas aperceptivas sejam semelhantes, sob pena de não haver compreensão entre elas:

\footnotetext{
Quanto mais elementos próximos nas massas aperceptivas entre os indivíduos, maior a aproximação e compreensão do discurso, o mesmo se inverte segundo o autor quanto se encontra distanciamento das massas aperceptivas, maior será a dificuldade encontrada. (JAKUBINSKIJ, 2015, p. 88)
}

O conteúdo da massa aperceptiva, vai determinar a maneira como se recebe as novas informações, e se o indivíduo vai compreender ou não o discurso de outra pessoa. Quanto mais semelhantes as vivências, a linguagem e o meio em que estão inseridos, maior a compreensão do discurso entre os indivíduos.

Mello (2015) defende que o ser humano deve ser apresentado à cultura mais elaborada. É esse contato com o novo que vai promover o desenvolvimento. Tendo como base a massa aperceptiva, quanto mais informações e novos aprendizados forem conquistados ao indivíduo, maior será o seu desenvolvimento.

Apesar de tratarem de linhas distintas (Jakubinskij - o discurso, e Vigotski - o desenvolvimento humano), a ideia central que norteia os conceitos é a mesma: a influência do meio social, ou seja, aquilo que a pessoa já vivenciou ou experimentou vai influenciar a maneira como 
ele receberá as novas informações que forem surgindo, vai determinar aquilo que serão capazes de compreender ou assimilar quando entrar em contato com novas informações.

Nesse sentido, os fundamentos da Teoria histórico-cultural nos ajudam a compreender de que maneira o ser humano vai criando e nutrindo sua massa aperceptiva; tudo o que ele traz consigo o limita ou o liberta na sua leitura do mundo e das situações que vão surgir na sua vida.

Para aprender, as crianças utilizam a abstração e a generalização substanciais para a dedução sucessiva (também com a ajuda do professor) de outras abstrações mais particulares e para sua união com o objeto integral (concreto) estudado. Quando os estudantes começam a utilizar a abstração e a generalização substanciais como meios para deduzir e unir outras abstrações, eles convertem as estruturas mentais iniciais (massa aperceptiva) em conceito (Davidov, 1988). Assim ela associa o que já traz consigo (massa aperceptiva) com o que está entrando em contato agora. As experiências anteriores que a pessoa vivenciou, de acordo com Jakubisnkij, permitem identificar novos conceitos linguísticos.

Falando em aprendizagem, pode-se associar este ponto à colocação de Vigotski a respeito da zona desenvolvimento próximo, mencionada anteriormente, que também apresenta uma relação com a afirmação de Jakubinskij sobre a massa aperceptiva.

Assim como não é possível que haja comunicação eficaz se as massas aperceptivas dos falantes estiverem muito distantes, uma ação muito distante da zona de desenvolvimento real da criança não poderá ser realizada, de forma que não adianta querer ensinar a uma criança algo muito distante do ponto em que ela se encontra. Uma criança só é capaz de aprender aquilo que está na zona de desenvolvimento proximal; coisas muito distantes não são assimiladas.

Da mesma forma uma pessoa só consegue entender a outra se o vocabulário ou dialeto dos falantes estiverem próximos, se o campo semântico for semelhante e se suas massas aperceptivas forem semelhantes. Logo, quanto mais elementos próximos nas massas aperceptivas entre os indivíduos, maior a aproximação e compreensão do discurso, (JAKUBINSKIJ, 2015). Um indivíduo não vai compreender o outro se suas experiências de linguagem não estiverem próximas. Os jargões das áreas específicas, a diferença social, os dialetos existentes não serão compreendidos por pessoas que não estão dentro daquela realidade específica. Em situações de grande distanciamento de massas aperceptivas ocorre uma dificuldade de comunicação, como se houvesse uma barreira. Quanto maior esse distanciamento, maior será a dificuldade encontrada, do mesmo modo, quanto maior a distância do que se quer ensinar à criança, daquilo que ela já sabe, maior será a dificuldade encontrada na aprendizagem.

O terceiro aspecto que é possível relacionar entre os teóricos comparados aqui, diz respeito à linguagem. Vigotski associa à linguagem a função reguladora do pensamento e ela é subdividida 
em significado e sentido, sendo que significado para ele é a unidade de análise da relação pensamento e linguagem, é um ponto imóvel e imutável que permanece estável em todas as mudanças de sentido da palavra em diferentes contextos (VIGOTSKI, 2009), já o sentido é sempre uma formação dinâmica, fluida, complexa que tem várias zonas de estabilidade, o sentido está ligado ao contexto em que a palavra aparece. O sentido é um aspecto particular do signo por ser formado a partir das relações interpessoais vivenciadas pelo indivíduo e da sua história. Nessa dinâmica surge um novo conceito: a significação, que segundo Leontiev (1978), pertence ao mundo dos fenômenos objetivamente históricos. Essa significação como conteúdo da consciência social seria o sistema de significações, são essas significações que fazem mediação entre o homem e o mundo, é através delas que o homem se apropria da cultura, pois elas já estão dadas socialmente e o homem apenas se apropria delas.

Ao sentido de Vigotski associa-se o de massa aperceptiva, pois ambas referem-se àquilo que o indivíduo traz consigo a partir das relações interpessoais que ele vivencia ao longo de sua vida. O sentido depende da história do indivíduo e do contexto no qual o diálogo ocorre; ele não preexiste, do mesmo modo que a massa aperceptiva é toda informação que o indivíduo carrega no momento de se comunicar (JAKUBINSKIJ, 2015).

\section{Conclusão}

Foi possível associar os conceitos dos dois teóricos aqui discutidos em três aspectos, o primeiro diz respeito à importância do meio social e das vivências de um indivíduo para o seu desenvolvimento humano, para que ele leia e interprete as novas circunstâncias diante das quais ele é exposto.

O segundo aspecto diz respeito à convergência de informações entre duas pessoas que se relacionam, conversam ou fazem parte do processo ensino-aprendizagem. Se as massas aperceptivas dos falantes forem semelhantes eles se compreenderão, se forem distantes, não haverá comunicação, ou essa ficará comprometida; quanto mais próximo for o conhecimento que se pretende ensinar a uma criança de sua zona de desenvolvimento real, mais facilmente ela assimilará o novo conhecimento e desenvolverá suas potencialidades humanas. Torna-se muito difícil a aprendizagem e o desenvolvimento se a lacuna entre o nível que o professor quer que seu aluno atinja for muito distante daquele que aluno se encontra no momento presente.

O terceiro aspecto aqui discutido é a relação do sentido vigotskiano que é sempre uma formação dinâmica, fluida, complexa e está ligado ao contexto em que a palavra aparece. O sentido depende da história do indivíduo e do contexto no qual o diálogo ocorre. Este artigo não pretende 
esgotar as possibilidades de comparação entre os conceitos aqui apresentados, mas apenas inicia uma discussão que pode se estender muito ainda.

\section{Referências}

AQUINO, O. F.; CUNHA, N. M. Concepção didática da tarefa de estudo: dois modelos de aplicação. In: BARBOSA, M. V.; MILLER, S.; MELLO, S. A. (orgs). Teoria histórico-cultural: questões fundamentais para a educação escolar, Marília: Oficina Universitária; São Paulo: Cultura Acadêmica, 2016. p.173-200.

GOLDFELD, M. A criança surda: linguagem e cognição numa perspectiva sociointeracionista. São Paulo: Plexus Editora, 1997.

JAKUBINSKIJ, L. Sobre a fala dialogal. São Paulo: Parábola, 2015.

LEONTIEV, A. N. O desenvolvimento do psiquismo. Lisboa: Livros Horizonte, 1978. 352 p.

LIMA, E. A. Trabalho pedagógico na Educação Infantil: em busca da atitude ativa de professores e crianças. In: MENDONÇA, S. G. L.; PENITENTE, L. A. A.; MILLER, S. (orgs). A questão do método e a Teoria Histórico-Cultural: bases teóricas e implicações pedagógicas. São Paulo: Cultura Acadêmica, 2017, p. 113-129.

LIMA, E. A. AKURI, J. G. M. Um Currículo e defesa da plenitude da formação humana. In: COSTA, S. A.; MELLO, S. A. (orgs). Teoria Histórico-Cultural na Educação Infantil: conversando com professoras e professores. Curitiba: CRV. 2017, p. 115-128.

MELLO, S. A. Contribuições da Teoria Histórico-Cultural para a educação da pequena Infância. Revista Cadernos de Educação. Pelotas, no 50, 2015. Disponível em:

$<$ https://periodicos.ufpel.edu.br/ojs2/index.php/caduc/article/viewFile/5825/4249>. Acesso em: 14 ago. 2017.

SAVIANI, D. Pedagogia Histórico-Crítica: primeiras aproximações. 9. ed. Campinas: Autores Associados, 2005.

TEIXEIRA, S.R.; BARCA, A. P. A. Teoria Histórico-Cultural e Educação Infantil: concepções para orientar o pensar e o agir docentes. In: COSTA, S. A.; MELLO, S. A. (orgs). Teoria Histórico Cultural na Educação Infantil: conversando com professoras e professores. Curitiba: CRV. 2017, p. 29-39.

VIGOTSKI, L. S. Aprendizagem e Desenvolvimento Intelectual na Idade Escolar. In: VIGOTSKII, L. S. et al. - Linguagem, desenvolvimento e aprendiragem. 12 ed. São Paulo: Ícone, 2012.

VIGOTSKI, L. S. Quarta aula: A questão do meio na pedologia. Psicologia USP, São Paulo, v. 21, n. 4, pp.681-702, out./dez., 2010.

VIGOTSKI, L. S. Obras Escogidas: Tomo III. (1984). 2 ed. Madrid: Machado Nuevo Aprendizaje, 2006. 
Recebido em: 02 jul. 2019 / Aprovado em: 31 out. 2019

\section{Para referenciar este texto}

BRANDÃO, Silvane Maria Pereira; LABADESSA, Vanessa Milani; LIMA Márcia Mendes de. Tecendo relações entre o conceito de "Massa Aperceptiva" de Jakubinskij e algumas ideias de Vigotski. Cadernos de Pós-graduacão, São Paulo, v. 18, n.2, p. 166-175, jul./dez. 2019. Disponível em: $<$ https://doi.org/10.5585/cpg.v18n2.14359>. 